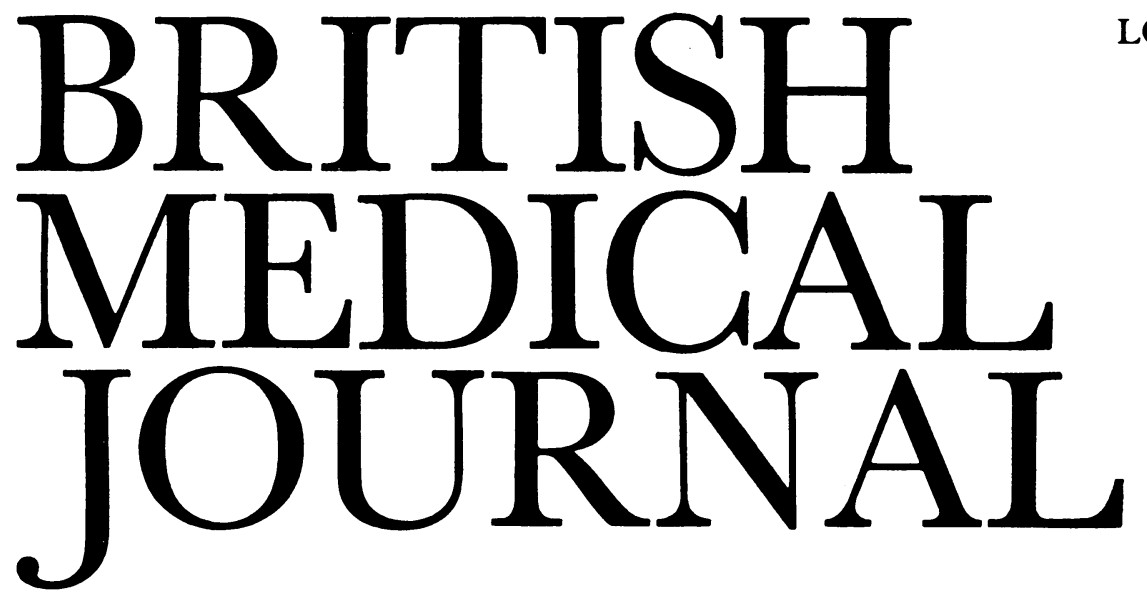

LONDON, SATURDAY 12 OCTOBER 1985

\title{
Working with visual display units
}

"In putting automation into practice, its very novelty, its unfamiliarity," warned the Reith lecturer some 20 years ago, "is likely to arouse instinctive caution on the part . . . of organised labour." Since then we have seen Sir Leon Bagrit's prophecy develop. Known at first as cathode ray tube display systems, they were used as computer terminals, for airline seat reservations systems, stock control, and research-but now the microprocessor has brought visual display units (VDUs) into offices and homes. It is the scale of expansion which is new, not the VDUs.

At first doctors were concerned largely with character size, resolution, and stability, although ergonomic factors such as lighting and the layout of the workplace also attracted attention. ${ }^{2}$ More recently VDUs have been alleged to be hazardous to health in several ways. Some of the hazards may be serious, others less so. Some of the allegations seem well founded, and again others less so.

The earlier complaints by operators of VDUs were concerned with visual problems and working posture. Traditional office lighting and furniture are designed for workers reading paper flat on a desk and are not necessarily right when they need to read characters on reflecting, vertical glass screens. The proper design of VDUs and the work stations where they are used is a necessary part of their installation. ${ }^{3}$ The problems are not unique: similar ergonomic considerations occur, for example, at check out points in supermarkets, ${ }^{4}$ but rigid adoption of "ideal" static postures for the operators is not the simple answer. ${ }^{5}$

As Sir Leon Bagrit prophesied, the novelty and unfamiliarity of this new technology have "aroused instinctive caution on the part of organised labour." Some of the agreements negotiated between trade unions and employers have codified these commonsense ergonomic considerations somewhat rigidly; in some instances they include provision for eyesight testing and corrective spectacles if necessary. ${ }^{6-8}$ There is no evidence that working with VDUs can harm the eyesight, but some agreements contain sensible provisions about sufferers from conditions such as migraine or epilepsy obtaining advice from the company's occupational physician. Whether negotiated industrial agreements should give numerical specifications for keyboard pressures, screen luminance, character size, minimum refresh rate, and glare from the screen ${ }^{9}$ may be questioned, but doctors should remember that the introduction of new technology is bound up with wider issues of industrial relations, including job security and the sharing of benefits in terms of increased pay and shorter hours. ${ }^{10}$

One early concern was over $x$ rays. Like television receivers, VDUs emit light by the sudden arrest of a beam of electrons aimed toward the viewer. The energy of the $x$ rays from VDUs is low (about $25 \mathrm{keV}$ ), ${ }^{11}{ }^{12}$ and they do not appear to be detectable beyond the glass screen of the tube. ${ }^{12-14}$ Other electromagnetic radiations including microwaves and ultraviolet emissions have been found to be either at background levels or well below international safety standards..$^{13}$

Another possible hazard is the triggering of seizures in patients with photosensitive epilepsy. This condition is rare, occurring in about one in 5000 people,${ }^{15}$ and the most likely age of onset is about 10 to 14 with most first attacks occurring before the age of $20 .^{3}$ The physical features of the stimulus such as brightness, size of screen, the frequency of picture repetition, and viewing distance make it unlikely that work with VDUs will provoke an attack, ${ }^{16}$ and so far only one case has been reported. ${ }^{15}$

Facial dermatitis in VDU operators appears as redness in the malar regions, sometimes preceded by itching, and developing within a few hours of leaving work. ${ }^{17-19}$ Later a few small papules may appear with slight scaling. The cause seems to lie in a combination of electrostatic fields ${ }^{3}$ and low humidity $\left(20 \%\right.$ in one report $\left.{ }^{18}\right)$. Modern office carpeting, if untreated, may cause an electrostatic charge of several kilovolts on people walking across it. ${ }^{20}$ Some VDU screens may develop an electrostatic potential of $10 \mathrm{kV}$ and the operator may develop one of $-0.6 \mathrm{kV}$. In the absence of good ventilation the resultant electrostatic fields may cause charged particles and air contaminants to be deposited on the face. ${ }^{192122}$ An antistatic mat or similar treatment to the carpet will alleviate the condition. And work in low humidity (about 20-30\%) may by itself give rise to "low humidity dermatosis." 23

More recently the emotive question of reproductive effects has emerged as another hazard attributed to work with VDUs. ${ }^{24}$ This began with reports from North America of several clusters of "adverse pregnancy outcome" (increase in miscarriages and birth defects) among women VDU operators. Miscarriages are not evenly spread in time and space, 
and some clustering is to be expected-so the occurrence of a few clusters proves nothing one way or the other. Unless we know the numbers of groups of VDU operators and their pregnancy outcomes (and we don't) we cannot draw useful conclusions from the present reports of clusters of miscarriages.

The answer might come from an epidemiological study, but it would be fraught with pitfalls. The confident recognition of early pregnancy (and early miscarriages) is not always easy. ${ }^{25}$ Other confounding factors include the previous history (earlier miscarriages increase the probability of a subsequent one ${ }^{2627}$ ), maternal age (the miscarriage rate is lowest between the ages of 26 and $29^{26}$ ), maternal smoking (which increases the miscarriage rate by as much as 1.7 times ${ }^{26} 2829$ ), selection bias (exposed and control groups are volunteers), and, finally, recall or response bias between the exposed and control groups. ${ }^{3031}$ The last point was well illustrated in a study of miscarriages among women working with anaesthetic gases, where the exposed group reported that $12.4 \%$ of pregnancies ended in spontaneous abortions compared with $9 \cdot 1 \%$ in the control group. ${ }^{30}$ Examination of the hospital records of non-responders showed that, whereas all of the exposed group who had miscarried had responded, 20 miscarriages in the control group had not been reported. When those were included the rate for the control group became $11 \%$.

We should not, therefore, be surprised that studies of miscarriages in operators of VDUs have given equivocal results. Alison McDonald and her colleagues reviewed groups whose occupations might require work with VDUs. ${ }^{32}$ In 2504 pregnancies in which a VDU had not been used the rate of spontaneous abortion was $5 \cdot 7 \%$. In 586 pregnancies in women using a VDU for fewer than 15 hours weekly it was $8.2 \%$, and in 709 pregnancies in women using VDUs for at least 15 hours weekly it was $9 \cdot 3 \%$. They found the same trend in all the occupational groups with potential use of VDUs which they studied. By contrast, the rate of spontaneous abortion in 5867 pregnancies in workers from groups not using VDUs was $7 \cdot 8 \%$. They cautioned that these results might be subject both to selection bias and to response bias. A recent comparison between 1475 mothers of malformed children and their paired referents found no evidence that exposure to VDUs caused birth defects. ${ }^{33}$ No mention was made in that report of miscarriages.

Thus the anecdotal reports of "clusters" of miscarriages among operators of VDUs and the equivocal results from epidemiological studies provide weak grounds for action which might cause widespread anxiety. What possible scientific explanations are available? Ionising radiation is not one, for it has been calculated that were a VDU screen to be emitting at the regulatory limit of $0.5 \mathrm{mrem}(5 \mu \mathrm{Sv}) / \mathrm{h}$ the total dose to the embryo in the first trimester would be about a quarter of that due to background radiation. ${ }^{11}$ Another possibility is an effect of the varying very low frequency electromagnetic fields generated by VDUs. The transformer and its associated circuits generate a "saw tooth" wave to give the horizontal sweep, but these are generally toward the back and to one side of the unit and emit electromagnetic radiation at about $15-25 \mathrm{kHz}$. The operator, seated in front, is shielded from the electrical component of that radiation by the video screen, but the magnetic component is not so readily screened. The magnetic field at the front of the screen varies from $13 \mathrm{mT} / \mathrm{s}$ at $30 \mathrm{~cm}$ falling to $0.8 \mathrm{mT} / \mathrm{s}$ at $100 \mathrm{~cm} .{ }^{34}$

An experimental study using $100 \mathrm{~Hz}$ rectangular magnetic pulses of $500 \mathrm{~ms}$ duration and $1 \cdot 2 \mu \mathrm{T}$ strength showed an increase in the number of abnormalities in 48 hour old chick embryos. ${ }^{35}$ The effect was greatest with pulses having a rate of change of about $24 \mathrm{mT} / \mathrm{s}^{36}$ (not grossly dissimilar from the figures above, though the frequencies were quite different) The effect was not observed at higher $(1000 \mathrm{~Hz})$ or lower $\left(10_{-}\right.$ $\mathrm{Hz}$ ) frequencies or at higher (for example, $100 \mu \mathrm{T}$ ) or lower (for example, $0.4 \mu \mathrm{T}$ ) pulsed field strengths, suggesting 200 "window" effect. Other workers who have claimed that thes magnetic fields in their experiments were comparable havee been unable to replicate those results, although it seems that: the magnetic fields they used had rates of change of $1.2 \mathrm{~T} / \mathrm{s}$ and $120 \mathrm{mT} / \mathrm{s} .{ }^{37}$ We can only speculate on the relevance of these findings to events inside a uterus within a human body some 30 to $100 \mathrm{~cm}$ from a VDU screen. If the concept of वृ window effect, particularly with regard to field strength, were to be established it would greatly complicate the task of epidemiologists looking for a conventional "dose effect", relation.

More, the figures just quoted are a thousandfold less than the limit of $20 \mathrm{~T} / \mathrm{s}$ for time varying magnetic fields (with $2 \mathrm{P}$ correction for short periods) recently recommended by the National Radiological Protection Board for nuclear magnetice resonance ${ }^{38}$ - though that recommendation is based on the possibility of the induction of minute electric currentso sufficient to cause depolarisation in nerve and muscle cellsio rather than on possible embryotoxic effects. Indeed, a note ofe caution appears in the National Radiological Protection Board guidelines: "Although there is evidence to suggest tha the developing embryo is not sensitive to magnetic fieldso encountered in nuclear magnetic resonance clinical imaging studies, yet to be confirmed, reported changes which could have developmental consequences. It was considered prudent therefore, on this tentative evidence, to exclude pregnanio women during the first trimester when organ development is taking place in the embryo until more conclusive evidence iso forthcoming."

Hence we can say that for work with VDUs some allegech hazards-such as ionising radiation and ultraviolet emissionsi -have been discounted, while others for which there is some evidence-such as mild facial dermatitis, photosensitive epilepsy, and the consequences of poor workplace ergonomics - may be dealt with satisfactorily. The allegations of reproductive hazards, and in particular spontaneous abor tion, remain neither proved nor, what is much more difficult disproved. The evidence is not strong and, while interesting, the possible mechanisms suggested may at present be regarded only as speculative.

Nevertheless, this is an issue which has attracted publicity, and doctors may find themselves in a familiar dilemma when faced by anxious patients. To encourage wholesale transfer from work with VDUs is to risk being thought of as accepting the hazard, while to refuse a transfer is to invite opposition and resistance, made worse in this case because any sub 0 sequent spontaneous abortions might well be blamed on thew VDU. In Sweden pregnant women may request to leave work with VDUs - and they may be allowed to do so on the grounds of reducing worry. ${ }^{39}$ In Britain the Trades Unions Congress has adopted a similar line by an argument which assumes a connection between worry and spontaneous abortion: "It has to be recognised that psychogenic factors of increased worry as a result of uncertainty about VDU work依 might, itself, prove a significant threat to the success of the pregnancy." 40

Should an association between work with VDUs anf̊ reproductive problems be established, and the evidence sof. far is not strong, then that will prove good advice. Should the association fail to be established, then all should cooperate in 
allaying any residual worries consequent on putting this piece of automation into practice, while the doctor reflects with Mark Twain that there is something fascinating about science as one gets such wholesome returns of conjectures out of such trifling investment of fact.

\section{W R LEE}

Professor of Occupational Health,

University of Manchester,

Manchester M13 9PT

1 Bagrit L. The age of automation. London: Weidenfeld and Nicholson, 1965:61.

2 Bruton DM. Medical aspects of cathode ray tube display systems. Transactions of the Society of

Occupational Medicine 1972;22:56-7.
3 Health and Safety Executive. London: Visual display units. HMSO, 1983.

3 Health and Safety Executive. London: Visual display units. HMSO, 1983. $1985 ; 6: 26-33$.

5 Starr SJ, Shute SJ, Thompson CR. Relating posture to discomfort in VDT use. $\mathcal{F}$ Occup Med 1985;27:269-71.

6 Anonymous. APEX gets agreement on VDUs at International Harvester and Coventry Climax. Health and Safety Information Bulletin 1980;54:5-7.

7 Anonymous. New APEX guidelines and ASTMS agreement on VDUs. Health and Safery Information Bulletin 1981;65:3-6.

8 Anonymous. National agreement on VDUs in the Civil Service. Health and Safery Information Bulletin 1983;93:5-9.

9 Anonymous. Official guide and new agreements on VDUs. Health and Safery Information Bulletin 1983;90:9.

10 Anonymous. VDUs, eyesight and operator welfare-an update. Health and Safery Information Bulletin 1982;83:2-5.

11 Hirning CR, Aitken JH. Cathode-ray tube $\mathrm{x}$-ray emission standard for video display terminals. Health Phys 1982;43:727-31.
Hirning CR, Aitken JH. Cathode

Health Phys 1982;43:727-31.
12 Pomroy C, Noel L. Low-background radiation measurements on video display terminals. Health Phys 1984;46:413-7.

13 Weiss MM, Petersen RC. Electromagnetic radiation emitted from video computer terminals. Am Ind Hyg Assoc f 1979;40:300-9.

14 Cox E. Electromagnetic radiation emissions from visual display units: a review. Displays Technology and Application 1983;4:7-10.

15 Jeavons PM, Harding GFA, Drasdo N, Furlong PLF, Bishop AI. Visual display units and epilepsy. Lancet $1985 ;$; :287.

16 Binnie CD, Kasteleijn-Nolst Trenite DGA, de Korte R, Wilkins A. Visual display units and risk of seizures. Lancet $1985 ; \mathrm{i}: 991$.

17 Rycroft RJG, Calnan CD. Facial rashes among visual display unit (VDU) operators. In: Pearce BG, ed. Health hazards of VDTs. London: Wiley, 1984:13-5.

18 Nilsen A. Facial rash in visual display unit operators. Contact Dermatitis 1982;8:25-8.

19 Tjonn HH. Report of facial rashes among VDU operators in Norway. In: Pearce BG, ed. Health hazards of VDTs. London: Wiley, 1984;17-23.

20 Lee WR. Little shocks. Practitioner 1981;225:1679-83.

20 Lee WR. Little shocks. Practitioner 1981;225:1679-83.
21 Bergqvist U. Physical and chemical environments at VDT work stations-air ions, electrostatic fields, magnetic fields and PCBs. In: Pearce BG, ed. Allegations of reproductive hazards from VDUs. Loughborough: Humane Technology, 1984:55-64.

22 Marha K. Electric and magnetic fields around VDTs-review of biological effects. In: Pearce BG, ed. Allegati: : of reproductive hazards from VDUs. Loughborough: Humane Technology, 1984:65-98.

23 Rycroft RJG, Smith WDL. Low humidity occupational dermatoses. Contact Dermatitis 1980;6 488-92.

24 Anonymous. Medical briefing. The screen of fear. The Times 1984 Nov 16:12 (cols 5-7).

25 Miller JF, Williamson E, Glue J, Gordon YB, Grudzinskas JG, Sykes A. Fetal loss after implantation-a prospective study. Lancet 1980;ii:554-6.

26 Knill Jones RP. Occupational factors and pregnancy outcome in doctors. London: Faculty of Community Medicine, 1980-9. (MFCM thesis.)

27 Strobino BR, Kline J, Shrout P, Stein Z, Susser M, Warburton D. Recurrent spontaneous abortion: definition of a syndrome. In: Porter IH, Hook EB, eds. Human embryonic and fetal abortion: definition of a syndrome. In: Porter IH,

28 Himmelberger DU, Brown BW, Cohen EN. Cigarette smoking during pregnancy and the occurrence of spontaneous abortion and congenital abnormality. Am $\mathcal{J}$ Epidemiol 1978;108
$470-9$.

29 Kline J, Stein Z, Susser $M$, Warburton D. Environmental influences on early reproductive loss in a current New York City study. In: Porter IH, Hook EB, eds. Human embryonic and fetal death New York: Academic Press, 1980:225-60.

30 Axelsson G, Rylander R. Exposure to anaesthetic gases and spontaneous abortion: response bias in a postal questionnaire study. Int $\mathcal{O}$ Epidemiol 1982;11:250-6.

31 Axelsson $G$, Rylander $R$. Validation of questionnaire reported miscarriage, malformation and birthweight. Int $\mathcal{J}$ Epidemiol 1984;13:94-8.

32 McDonald AD, Cherry NM, Delorme C, McDonald JC. Work and pregnancy in Montreal-preliminary findings on work with visual display terminals. In: Pearce BG, ed. Allegations of reproductive hasards from VDUs. Loughborough: Humane Technology, 1984:161-75.

33 Kurppa A, Holmberg PC, Rantala K, Nurminen T. Birth defects and video display terminals. Lancet 1984;ii: 1339 .

34 Paulsson LE, Kristiansson I, Malmstrom I. Radiation from data screens. Arbetsdokument a 84-08, Radiation Protection Board, Stockholm, Sweden. Cited by Bergqvist U. In: Pearce BG ed. Allegations of reproductive hazards from VDUs. Loughborough Humane Technology, 1984 55-64.

35 Delgado JMR, Leal J, Monteagudo JL, Gracia MG. Embryological changes induced by weak, extremely low frequency electro-magnetic fields. I Anat 1982;134:533-51.

36 Ubeda A, Leal J, Trillo MA, Jimenez MA, Delgado JMR. Pulse shape of magnetic field influences chick embryogenesis. F Anat 1983;137:513-36.

37 Maffeo S, Miller MW, Carstensen EL. Lack of effect of weak low frequency electromagnetic fields on chick embryogenesis. F Anat 1984;139:613-8.

38 Saunders RD, Smith H. Safety aspects of NMR clinical imaging. Br Med Bull 1984;40:148-54.

39 Bergqvist U, Knave B. Video display work and pregnancy-research in the Nordic countries. In Pearce BG, ed. Allegations of reproductive hazards from VDUs. Loughborough: Humane Pearce BG, ed. Allegations
Technology, 1984:49-53.

40 Bayne VJ. Paper outlining a trade union response to the allegations of reproductive hazards from VDUs. In: Pearce BG, ed. Allegations of reproductive hazards from VDUs. Loughborough: Humane Technology, 1984:111-26.

\section{Children in accident and emergency departments}

Eighteen years ago the $B M \mathcal{F}$ published a memorandum on the management of accidents in childhood prepared by the Standing Committee on Accidents in Childhood of the British Paediatric Association. ${ }^{1}$ Recently this committee (now a joint committee of the British Paediatric Association and the British Association of Paediatric Surgeons) surveyed the facilities for children in accident and emergency departments and looked at the part played by paediatricians in their management (report obtainable from the British Paediatric Association, 23 Queen Square, London WCIN 3AZ to 31 October, 5 St Andrew's Place, London NW1 4LE thereafter). In the intervening years the specialty of accident and emergency medicine has developed, and great improvements have been made in facilities and the standard of care. Unfortunately, this new survey has shown that so far as children are concerned there are still many deficiencies.

The questionnaire was sent to paediatricians rather than to consultants in accident and emergency medicine, and replies were received relating to 189 hospitals out of the 258 hospitals with large accident and emergency departments. The first deficiency noted was that only 123 of the 189 hospitals kept a record of the number of children attending: one third made no attempt to estimate the demand on their services by children's attendances. The 123 hospitals had a total annual attendance of about one million children, indicating a total of two million in Britain, a figure that agrees reasonably well with other estimates. That is twice the number attending as paediatric outpatients. ${ }^{2}$ In 63 districts the main paediatric facilities were in a different hospital from the accident and emergency department, and in 23 there were no inpatient facilities of any sort for children. In some instances the distance between the accident and emergency department and the main paediatric unit was substantial-in nine cases, 10 miles $(16 \mathrm{~km})$ or more-a dangerous state of affairs, for sick or injured children would need to be moved considerable distances before they were admitted.

One hundred and five of the 189 hospitals had an accident and emergency consultant, but regular sessional commitment by paediatricians on their staff was rare: only 13 hospitals had such an arrangement, six in separate children's hospitals, three in children's accident and emergency departments alongside adult departments, and only four in general accident and emergency departments. Only $15 \%$ of hospitals had a registered sick children's nurse on the establishment, but perhaps surprisingly $47 \%$ had a liaison health visitor. A separate waiting area for children was provided in one quarter and a children's treatment room in the same proportion. Comments on interprofessional relationships were asked for: these admittedly were subjective, but on the whole were favourable, particularly with accident and emergency consultants. Problems with administration and staffing were common, however, shortage of junior staff being regarded as a limiting factor preventing an increased paediatric input into accident and emergency work.

Clearly there is room for improvement in the contribution of paediatricians to the care of children attending accident and emergency departments and in the facilities for their treatment. Paediatricians should surely be able to advise about the general management of children and their special needs compared with adults, and the very large numbers warrant a consultant paediatrician being appointed to share 